\title{
Nivolumab plus ipilimumab versus nivolumab in individuals with treatment- naive programmed death-ligand 1 positive metastatic soft tissue sarcomas: a multicentre retrospective study
}

Yaolin Chen ${ }^{1 \dagger}$, Xiangzhen Liư ${ }^{2 \dagger}$, Jijun Liu', Donghua Liang ${ }^{1}$, Mingdong Zhao ${ }^{3}$, Weiguang $\mathrm{Yu}^{4^{*}}$ and Pengfei Chen ${ }^{1 *}$

\begin{abstract}
Background: Currently, the choice of treatment for individuals with metastatic soft tissue sarcomas (MSTS) presents a significant challenge to clinicians. The aim of this retrospective study was to assess the efficacy and safety of nivolumab plus ipilimumab (NPI) versus nivolumab alone (NIV) in individuals with treatment-naive programmed death-ligand 1 (PD-L1) positive MSTS.
\end{abstract}

Methods: Prospectively maintained databases were reviewed from 2013 to 2018 to assess individuals with treatment-naive PD-L1 MSTS who received NPI (nivolumab $3 \mathrm{mg} / \mathrm{kg}$ and ipilimumab $1 \mathrm{mg} / \mathrm{kg}$ every 3 weeks for 4 doses followed by nivolumab $3 \mathrm{mg} / \mathrm{kg}$ every 2 weeks) or NIV (3 mg/kg every 2 weeks) until disease progression, withdrawal, unendurable [AEs], or death. The co-primary endpoints were overall survival (OS) and progression-free survival (PFS).

Results: The median follow-up was 16.0 months (IQR 14.4-18.5) after targeted intervention. The median OS was 12.2 months ( $95 \%$ confidence interval $[\mathrm{Cl}], 6.1-13.7)$ and 9.2 months $(95 \% \mathrm{Cl}, 4.2-11.5)$ for the NPI and NIV groups, respectively (hazard ratio [HR] 0.49, 95\% Cl, 0.33-0.73; $p=0.0002$ ); the median PFS was 4.1 months $(95 \% \mathrm{Cl}, 3.2-4.5$ ) and 2.2 months $(95 \% \mathrm{Cl}, 1.1-3.4)$ for the NPI and NIV groups, respectively (HR 0.51, 95\% Cl, 0.36-0.71; $p<0.0001)$. Key grade 3-5 AEs occurred more frequently in the NPI group than in the NIV group (94 [72.9\%] for NPI vs. 35 [27.1\%], $p<0.001)$.

Conclusions: For treatment-naive PD-L1 positive MSTS, NPI seems to be less tolerated but has a greater survival advantage than NIV as the primary therapy.

Keywords: Overall survival, Adverse events, Metastatic, Sarcoma, Treatment

\footnotetext{
*Correspondence: yuwg3@mail.sysu.edu.cn; chenpengfei0409@163.com

†Yaolin Chen and Xiangzhen Liu contributed equally to this work.

${ }^{4}$ Department of Orthopaedics, The First Affiliated Hospital, Sun Yat-sen

University, No. 58, Zhongshan 2nd Road, Yuexiu District, Guangzhou 510080,

China

'Department of Orthopaedics, Henan Provincial People's Hospital,

Department of Orthopaedics of Central China Fuwai Hospital,Central China

Fuwai Hospital of Zhengzhou University, No. 1, Fuwai Avenue, Zhengdong

New District, Zhengzhou 450003, China

Full list of author information is available at the end of the article
}

(c) The Author(s). 2021 Open Access This article is licensed under a Creative Commons Attribution 4.0 International License, which permits use, sharing, adaptation, distribution and reproduction in any medium or format, as long as you give appropriate credit to the original author(s) and the source, provide a link to the Creative Commons licence, and indicate if changes were made. The images or other third party material in this article are included in the article's Creative Commons licence, unless indicated otherwise in a credit line to the material. If material is not included in the article's Creative Commons licence and your intended use is not permitted by statutory regulation or exceeds the permitted use, you will need to obtain permission directly from the copyright holder. To view a copy of this licence, visit http://creativecommons.org/licenses/by/4.0/ The Creative Commons Public Domain Dedication waiver (http://creativecommons.org/publicdomain/zero/1.0/) applies to the data made available in this article, unless otherwise stated in a credit line to the data. 


\section{Background}

Soft tissue sarcoma (STS) is a heterogeneous malignant tumour derived from mesenchymal cells that displays a heterogeneous mix of clinical and pathologic characteristics and is largely resistant to conventional therapies [1-3]. Evidence-based statistics [4, 5] have indicated that the majority of individuals with STS tend to develop recurrent or metastatic disease and are associated with poor outcomes. Few, if any, chemotherapy regimens, either alone or in combination, can reverse this situation [6]. For individuals with treatment-naive metastatic STS (MSTS), several approved chemotherapy regimens (i.e., doxorubicin, either alone or in combination) seem to have similar effects, with a low response rate, progression-free survival (PFS) of nearly 0.5 years and overall survival (OS) of 1-1.5 years [7, 8]. Except for first-line chemotherapeutics, all other chemotherapeutics that have been approved, to a certain extent, have improved OS in the absence of progression or metastasis of the STS [9, 10]. However, for MSTS, the median PFS tends to be approximately 4 months, and OS from a diagnosis of MSTS is less than 14 months [7, 11]. Management of such individuals is still a challenge, and a poor prognosis seems to be inevitable [5].

Nivolumab, a fully human immunoglobulin G4PD-1 immune checkpoint-blocking antibody, explicitly binds to programmed death $1(\mathrm{PD}-1)$ and interrupts negative signalling to restore $\mathrm{T}$-cell anti-tumour function, which leads to improved survival and a promising safety profile in individuals with specific progressed solid tumours involving STS [7, 11, 12]. Findings from a recent randomized clinical trial [7] demonstrated that nivolumab, alone or combined with ipilimumab (a cytotoxic T-lymphocyte antigen-4 checkpoint inhibitor), had promising efficacy for specified sarcoma subtypes, with a controllable safety profile consistent with current confirmed alternatives. However, there is a paucity of published information regarding the utilization of nivolumab and/or ipilimumab in treatment-naive programmed death-ligand 1 (PD-L1) positive MSTS individuals [11]. We report herein a retrospective study assessing the efficacy and safety of nivolumab alone or combined with ipilimumab in this setting.

\section{Methods}

\section{Study design and patient eligibility}

Clinical data of treatment-naive PD-L1 MSTS patients were identified retrospectively from a registry database involving three medical institutions from January 1, 2013 to December 31, 2018. The cohort consisted of 214 individuals with histologically confirmed, unresectable, treatment-naive MSTS who were treated with nivolumab plus ipilimumab (NPI: nivolumab $3 \mathrm{mg} / \mathrm{kg}$ and ipilimumab $1 \mathrm{mg} / \mathrm{kg}$ every 3 weeks for 4 doses followed by nivolumab $3 \mathrm{mg} / \mathrm{kg}$ every 2 weeks) or nivolumab alone (NIV: nivolumab $3 \mathrm{mg} / \mathrm{kg}$ every 2 weeks) until disease progression, withdrawal, unendurable AEs, or death [7]. The key inclusion criteria were as follows: age $\geq 16$ years; a histologically definite diagnosis of STS with at least one measurable lesion per Response Evaluation Criteria in Solid Tumours (RECIST) v1.1 [8]; PD-L1 positive STS in the primary tissue; untreated MSTS; acceptable organ function (i.e., heart, liver, and kidney); and an Eastern Cooperative Oncology Group performance status of 0 or 1. The key exclusion criteria included a lack of baseline data; chemotherapy, radiotherapy, or surgery for MSTS prior to treatment; an interruption initiated by a nondrug itself in the NPI or NIV regimen; symptomatic central nervous metastasis; severe metabolic disorders (i.e., hyperthyroidism and hypophysoma); drug abuse; psychosis, or cognitive disorder.

\section{Outcomes and assessments}

PD-L1 expression on biopsy was assessed by immunochemistry using the anti PD-L1 monoclonal antibody, which was consistent with the previous description [13]. Positive PD-L1 expression was defined as staining of the plasma membrane in more than $1 \%$ of tumour cells [14]. OS was defined as the time from first dose to the date of death; PFS, from first dose to progression or death due to any cause, whichever came first. Drug toxicity analysis was performed using the approved product label for all evaluable patients who had undergone NPI or NIV treatment. Tumour responses were judged every 6 weeks until progression or drug interruption per RECIST v1.1. The RECIST was measured retrospectively. AEs were coded per the Medical Dictionary for Regulatory Activities (v 19.0). AE severity was graded per the Common Terminology Criteria for Adverse Events, v4.0 [7]. Follow-up was conducted every 2 months.

\section{Statistical analysis}

We used the chi-square test for categorical data; continuous variables were compared with Student t-test for normally distributed variables and Mann-Whitney U test for non- normally distributed variables. Median followup was estimated using the reverse Kaplan-Meier method. OS and PFS were estimated per the KaplanMeier method. Hazard ratios (HRs) were estimated by a Cox proportional hazard model with $95 \%$ confidence intervals (CIs). All $p$ values were two-sided with the level of significance set to 0.05 . We executed data analyses using SPSS v 26.0 (IBM, Inc., NY, USA).

\section{Results}

Comparison of baseline data

A total of 214 patients with treatment-naive PD-L1 positive MSTS were reviewed, 64 of whom were deemed to 
be ineligible according to our criteria, leaving $150 \mathrm{pa}$ tients (NPI: $n=74$, median age 35 years [21.2-51.8] and NIV: $n=76$, median age 34 years [23.8-57.3]) who were finally included for eligibility (Fig. 1). Of the 150 evaluable patients whose PD-L1 expression was validated, 150 (100\%) suffered PD-L1-positive tumours. Baseline data reported here were well balanced between groups (Table 1). Patients underwent a median 6 drug cycles (IQR 2.0-8.0), with a median follow-up period of 16.0 months (IQR 14.4-18.5) after targeted intervention.

\section{Comparison of efficacy}

A significant difference was observed in the proportion of patients with a confirmed response rate $(13 \%$ [95\% CI, 1-17] for NPI vs. 7\% [95\% CI, 1-11] for NIV). At the final analysis, individuals with unresectable, treatmentnaive MSTS who experienced NPI had a median OS of 12.2 months (95\% CI, 6.1-13.7), which was significantly longer than that of patients receiving NIV (9.2 months, 95\% CI, 4.2-11.5). The distinction in OS corresponded to an HR of 0.49 (95\% CI, 0.33-0.73, $p=0.0002$ ) (Fig. 2). A significant difference was also detected in median PFS (4.1 months [95\% CI, 3.2-4.5] for NPI vs. 2.2 months [95\% CI, 1.1-3.4] for NIV; HR 0.51, 95\% CI, 0.36-0.71; $p<0.0001)$, as shown in Fig. 3. The survival advantage of NPI versus NIV was more dramatic.

\section{Adverse events}

All 150 individuals included who underwent NPI or NIV treatment suffered AEs of any grade. The key grade 3-5 AEs observed were shown in Table 2. At the time of this analysis, key grade 3-5 AEs occurred more frequently in the NPI group than in the NIV group (94 [72.9\%] for NPI vs. 35 [27.1\%], $p<0.001)$. Discontinuation of NPI or NIV associated with AEs occurred in six (14\%) of 74 patients in the NPI group and one (2\%) of the 76 patients in the NIV group. Hyponatraemia occurred in 9 patients $(12.2 \%)$ in the NPI group and $1(1.3 \%)$ in the NIV group $(p=0.008)$. Hypotension was more frequent in the NPI group than in the NIV group $(8[10.8 \%]$ vs. $0[0.0 \%]$, respectively, $p=0.003$ ). Significant differences were also observed in terms of increased aspartate aminotransferase (5 [6.8\%] for NPI vs. 0 [0.0\%] for NIV, $p=0.021$ ), dyspnoea (6 [8.1\%] for NPI vs. 0 [0.0\%] for NIV, $p=0.011$ ), nervous system disorders $(8$ [10.8\%] for NPI vs. 1 [1.3\%] for NIV, $p=0.014)$, urinary tract infection (4 [5.4\%] for NPI vs. $0[0.0 \%]$ for NIV, $p=0.040)$, and $\geq 2$ AEs in a patient $(23$ [31.1\%] for NPI vs. 12 [15.8\%] for NIV, $p=$

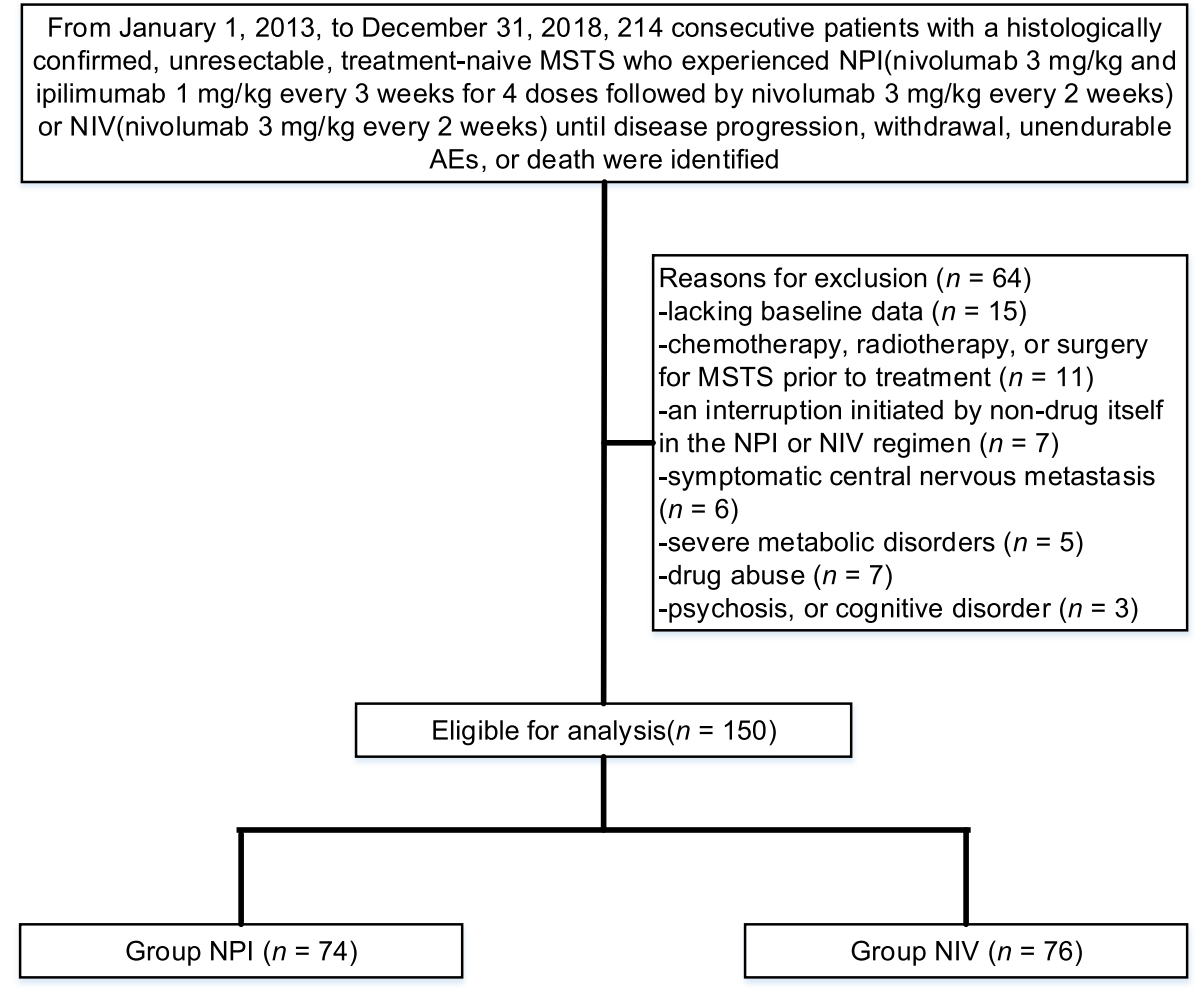

Fig. 1 Flow diagram demonstrating the methods used for the identification of this study to retrospectively assess the efficacy and safety of nivolumab plus ipilimumab (NPI) versus nivolumab alone (NIV) in individuals with untreated programmed death-ligand 1 (PD-L1) positive MSTS 
Table 1 Patient demographics and disease characteristics at baseline

\begin{tabular}{|c|c|c|c|}
\hline Variable & NPI $(n=74)$ & NIV $(n=76)$ & $p$-value \\
\hline \multicolumn{4}{|l|}{ Age, years } \\
\hline Median (range) & $35(21.2-51.8)$ & $34(23.8-57.3)$ & 0.105 \\
\hline Sex, n (\%) & & & 0.729 \\
\hline Male & $42(56.8)$ & $41(53.9)$ & \\
\hline Female & $32(43.2)$ & $35(46.1)$ & \\
\hline \multicolumn{4}{|l|}{$\mathrm{BMI}, \mathrm{kg} / \mathrm{m}^{2}$} \\
\hline Median (range) & $25.7(17.1-41.3)$ & $25.4(15.6-43.7)$ & 0.256 \\
\hline ECOG performance status, n (\%) & & & 0.619 \\
\hline 0 & $40(54.1)$ & $38(50.0)$ & \\
\hline 1 & $34(45.9)$ & $38(50.0)$ & \\
\hline Sarcoma types ${ }^{a}, \mathrm{n}(\%)$ & & & 0.764 \\
\hline Non-uterine leiomyosarcoma & $43(58.1)$ & $40(52.6)$ & \\
\hline Liposarcoma $^{\mathrm{b}}$ & $20(27.0)$ & $22(28.9)$ & \\
\hline Synovial sarcoma & $11(14.9)$ & $14(18.4)$ & \\
\hline Three major types of liposarcoma & & & 0.078 \\
\hline Atypical lipoma & $9(12.1)$ & $11(14.5)$ & \\
\hline Myxoid liposarcoma & $10(13.5)$ & $9(11.8)$ & \\
\hline Pleomorphic liposarcoma & $1(1.4)$ & $2(2.6)$ & \\
\hline Histological grade, n (\%) & & & 0.504 \\
\hline G1 (well differentiated) & $31(41.9)$ & $37(48.7)$ & \\
\hline G2 (moderately differentiated) & $27(36.5)$ & $21(27.6)$ & \\
\hline G3 (poorly differentiated) & $16(21.6)$ & $18(23.7)$ & \\
\hline TMB $^{\mathrm{C}}$ status (per Mb), n (\%) & & & 0.716 \\
\hline TMB-High (> 5) & $45(60.8)$ & $44(57.9)$ & \\
\hline TMB-Low (0-5) & $29(39.2)$ & $32(42.1)$ & \\
\hline \multicolumn{4}{|l|}{ Duration of treatment (months) } \\
\hline Median (range) & $3(1.5-4.4)$ & $3(1.6-4.7)$ & 0.317 \\
\hline Number of metastatic sites, n (\%) & & & 0.583 \\
\hline 3 & $12(16.2)$ & $10(13.2)$ & \\
\hline$>3$ & $51(68.9)$ & $58(76.3)$ & \\
\hline Unknown & $11(14.9)$ & $8(10.5)$ & \\
\hline
\end{tabular}

${ }^{\mathrm{a}}$ Based on a central review of pathology; ${ }^{\mathrm{b}}$ Primary liposarcomas were located in the lower extremity (11\%), upper extremity (6\%), the trunk wall (11\%), the retroperitoneum (64\%), and the head and neck (8\%); ' defined as the number of somatic coding base substitution and indels per megabase of genome. NPI nivolumab plus ipilimumab, NIV nivolumab, BMI body mass index, ECOG Eastern Collaborative Oncology Group, TMB tumour mutation burden

0.027). The most frequent grade $\geq 3 \mathrm{AE}$ was anaemia, which occurred in 9 patients (12.2\%) in the NPI group and $8(10.5 \%)$ in the NIV group $(p=0.752)$. In addition, no significant differences were detected in regard to colonic perforation, increased creatinine, dehydration, vaginal fistula, increased lipases, lung infection, nausea, or skin infection. Drug-related deaths did not occur in either group.

\section{Discussion}

This study shows that for treatment-naive PD-L1 positive MSTS, the superiority of NPI over NIV in terms of survival benefit tends to be positive, which is in line with previous reports involving individuals with untreated MSTS $[7,11]$. Safety profiles were consistent with those of other solid tumours (i.e., melanoma) [15].

Our findings might provide a confirmation that NPI improves survival for individuals with untreated MSTS. In a multicentre, open-label, non-comparative, randomized phase 2 study [7], 85 eligible patients with metastatic sarcoma who were treated using NPI (42 cases) or NIV (43 cases) showed a median PFS of 4.1 months (2.6-4.7) and 1.7 months (95\% CI 1.4-4.3), respectively; the median OS was 14.3 months (9.6-not reached) with 


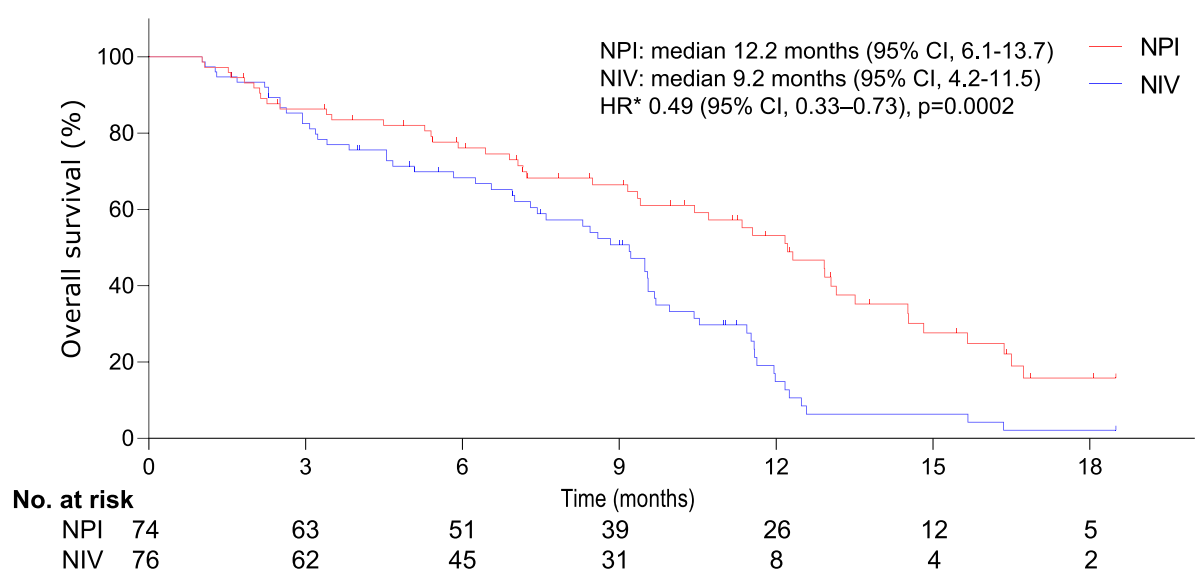

Fig. 2 Kaplan-Meier curves for overall survival. The median overall survival was 12.2 months (95\% Cl, 6.1-13.7) and 9.2 months (95\% Cl, 4.2-11.5) for the NPI and NIV groups, respectively ( $\mathrm{HR} 0.49,95 \% \mathrm{Cl}, 0.33-0.73 ; p=0.0002$ ). Significant differences were detected in the overall survival between groups. *The hazard ratio was calculated using a Cox proportional hazards model, with age, the sarcoma types, the number of metastatic sites, and the ECOG performance status as covariates and NPI or NIV therapy as the time-dependent factor

NPI and 10.7 months (5.5-15.4) with NIV. These findings may be instructive when placed in the context of presently accessible treatment options for individuals with untreated MSTS [16]. The classic treatment for MSTS tends to be based on cytotoxic chemotherapy, with first-line therapy predictably accomplishing objective responses in $15-18 \%$ of individuals, with a median PFS of 4-6 months $[7,17]$. Activity beyond the first-line options tends to decline, with less than $10 \%$ of individuals reaching objective responses and a median PFS of $1-4$ months [18]. In the current review, the choice of NPI or NIV as a monotherapy, regardless of its combination with cytotoxic chemotherapy, may have a negative impact on survival. However, a key challenge with MSTS is that well-established protocols for management tend to be lacking, and in the absence of distinguishable signs or symptoms identifiable by the clinicians, diagnosis tends to be difficult; indeed, once diagnosed with STS, the patient is generally in the late stage of the disease, ultimately leading to reduced survival $[16,19]$.

A double-blind trial [20] involving 142 patients with treatment-naive MSTS showed that meaningfully longer PFS was detected with NPI than with ipilimumab monotherapy (not reached vs. 4.4 months [95\% CI 2.8-5.7]; HR $0.40,95 \%$ CI $0.23-0.68, p<0.001)$. The response rate associated with NPI in their study (61\%) was higher than with NIV (61\% vs. $40 \%)$ as first-line therapy in such individuals. The response rate of the combination therapy in

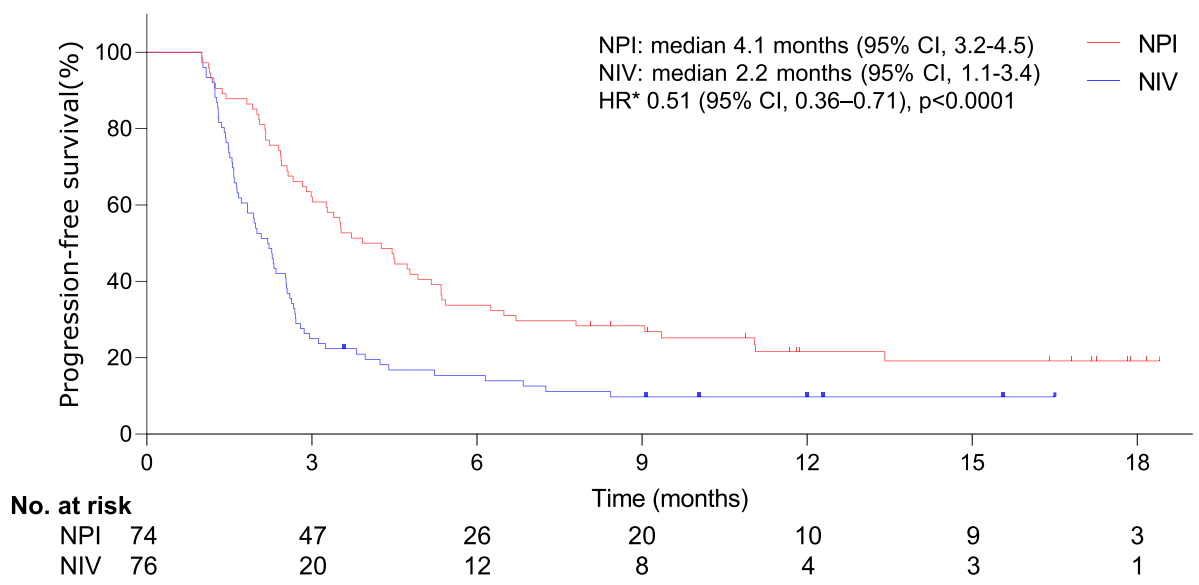

Fig. 3 Kaplan-Meier curves for progression-free survival. The median progression-free survival was 4.1 months (95\% Cl, 3.2-4.5) and 2.2 months (95\% Cl, 1.1-3.4) in the NPI or NIV groups, respectively (HR 0.51, 95\% Cl 0.36-0.71; $p<0.0001$ ). Statistically significant differences were detected in the progression-free survival between groups. *The hazard ratio was calculated using a Cox proportional hazards model, with age, the sarcoma types, the number of metastatic sites, and the ECOG performance status as covariates and NPI or NIV therapy as the time-dependent factor 
Table 2 Comparison of the incidence of key drug-related grade $\geq 3$ AEs at final follow-up

\begin{tabular}{|c|c|c|c|}
\hline Event, n (\%) & NPI $(n=74)$ & NIV $(n=76)$ & $p$-value \\
\hline Anaemia & $9(12.2)$ & $8(10.5)$ & 0.752 \\
\hline Aspartate aminotransferase increased & $5(6.8)$ & $0(0.0)$ & $0.021^{\mathrm{a}}$ \\
\hline Colonic perforation & $0(0.0)$ & $1(1.3)$ & 1.000 \\
\hline Creatinine increased & $2(2.7)$ & $2(2.6)$ & 0.978 \\
\hline Dehydration & $3(4.1)$ & $1(1.3)$ & 0.298 \\
\hline Dyspnoea & $6(8.1)$ & $0(0.0)$ & $0.011^{\mathrm{a}}$ \\
\hline Hyponatraemia & $9(12.2)$ & $1(1.3)$ & $0.008^{\mathrm{a}}$ \\
\hline Hypotension & $8(10.8)$ & $0(0.0)$ & $0.003^{\mathrm{a}}$ \\
\hline Vaginal fistula & $3(4.1)$ & $0(0.0)$ & 0.076 \\
\hline Lipases increased & $4(5.4)$ & $4(5.3)$ & 0.969 \\
\hline Lung infection & $3(4.1)$ & $3(3.9)$ & 0.973 \\
\hline Nausea & $4(5.4)$ & $2(2.6)$ & 0.386 \\
\hline Nervous system disorders & $8(10.8)$ & $1(1.3)$ & $0.014^{\mathrm{a}}$ \\
\hline Skin infection & $3(4.1)$ & $0(0.0)$ & 0.076 \\
\hline Urinary tract infection & $4(5.4)$ & $0(0.0)$ & $0.040^{\mathrm{a}}$ \\
\hline$\geq 2 \mathrm{AEs}$ in one patient & $23(31.1)$ & $12(15.8)$ & $0.027^{\mathrm{a}}$ \\
\hline
\end{tabular}

${ }^{a}$ Statistically significant. AEs adverse events, NPI nivolumab plus ipilimumab, NIV nivolumab

our study was also higher than the rate detected in published trials involving anti-PD-1 agent-based monotherapy (i.e., pembrolizumab) [21, 22]. Nevertheless, a comparison of the efficacy of NPI and anti-PD-1 monotherapy may be challenging due to differences in the baseline data of individuals among the studies. The PFS and OS seen with NPI in our review are in accordance with those reported elsewhere [7, 11, 23], with the primary endpoint occurring by the time of the final tumour evaluation and, in a host of patients, OS being prolonged as follow-up continued regardless of termination of treatment, which might be elucidated by the fact that the individuals included in this review were diagnosed with treatment-naive MSTS.

Antibodies against PD-1 or PD-L1 have a positive effect in blocking tumour immune evasion and inducing tumour regression in STS [7, 24]. Previous reports [7, $11,25,26]$ of PD-L1 expression have shown that STS is potentially responsive to PD-1/PD-L1 blockade intervention in STS patients with PD-L1 positivity. The survival benefit of NIV monotherapy is inconsistent with presently existing chemotherapy-based untargeted therapies $[7,11]$. Furthermore, in previous trials [8, 23], NIV patients failed to meet the predetermined primary outcome of completing responses in more than $13 \%$ of cases to sustain activity in their setting, which could exclude extended trials for heavily treated, unselected patients with MSTS $[11,16]$. NPI patients met this predetermined primary outcome among those unselected patients with MSTS [24, 26, 27]. The proportion of NPI patients reaching an objective response appeared to be $16 \%$, approximating that realized via accepted chemotherapybased management [26, 27]. Additionally, an objective response of approximately $16 \%$ in 38 patients is in accordance with FDA-approved chemotherapy regimens, theoretically favouring future trials of NPI not only as second-line management in patients with MSTS but also as a first-line treatment option $[7,26]$. Although patients undergoing a treatment regimen approved by the FDA exhibited a median OS of 26.5 months (95\% CI, 20.9$31.7)$, their data might not truly reflect survival in an open-label phase $1 \mathrm{~b}$ and randomized phase 2 trial [28]. However, the OS seen with NPI in this study is promising and indicates the potential to improve survival in patients with MSTS.

The safety results associated with NPI and NIV were in accordance with prior studies [7, 26]. In this review, NIV tended to be better tolerated, with a lower rate of AEs compared with NPI. The rate of grade 3-5 AEs among individuals experiencing NIV was $27.1 \%$. The safety results contrasted with the results reported in a previous study [7], where the dose of NIV was higher than the recommended dose, and a higher percentage of individuals suffered from grade 3-5 AEs. Adopting a lower dose of NIV could potentially improve the rate of AEs. Remarkably, the proportion of grade 3-5 AEs described in this review for NIV was lower than that of cytotoxic drugs in the current setting.

Several limitations should be recognized in this review. First, this study is a retrospective study, with its inherent shortcomings and some potential confounding variables (i.e., potential comorbidities and complications, some 
patients who were followed up by telephone), which reduces the reliability of the conclusion. Second, the sample size of this retrospective review is limited, which restricts the generalizability of the results to some extent. Third, gene mutation types are not retested when the disease progresses, and drug resistance mutations during treatment have not been tested for each individual. Therefore, when drug resistance mutations appear in some individuals, the power of this study to reach a reliable conclusion is weakened. Fourth, the current research objects were collected from different tertiary medical centres, and there might be some differences in the diagnosis process of these medical institutions. Nevertheless, these research objects are coded and combined through standardized methods, which guarantees the reliability of the research conclusions.

\section{Conclusion}

The results reported in the current review reiterate an increasing body of evidence showing that for individuals with treatment-naive PD-L1 positive MSTS who undergo treatment with NPI or NIV, NPI seems to be less tolerated but has a greater survival advantage as the primary therapy than NIV. Our findings might underline the promise of combined checkpoint inhibition in the current setting. These data should be validated prospectively in subsequent analyses of larger cohorts with treatment-naive MSTS.

\section{Abbreviations \\ MSTS: Metastatic soft tissue sarcomas; NPI: Nivolumab plus ipilimumab; NIV: Nivolumab; AEs: Adverse events; OS: Overall survival; PFS: Progression- free survival; IQR: Interquartile range; PD-1: Programmed death 1; Cls: Confidence intervals; HRs: Hazard ratios; RECIST: Response Evaluation criteria in solid tumours; ECOG PS: Eastern Collaborative Oncology Group performance status; PD-L1: Programmed death-ligand 1; TMB: Tumour mutation burden}

\section{Acknowledgments}

Not applicable.

\section{Authors' contributions}

$Y C, X L, W Y$, and PC: Planning and study design. JL, DL, and MZ: Study execution, statistical analysis, and writing-initial draft. YC and WY: Planning and study design, and writing-final revision. All authors have read and approve the final version.

\section{Funding}

This work received no specific grant from any funding agency in the public, commercial, or not-for-profit sectors.

\section{Availability of data and materials}

The datasets used during the current study are available from the corresponding author on reasonable request.

\section{Ethics approval and consent to participate}

The retrospective study was approved by the Institutional Review Boards (IRBs) of each participating hospital; and written informed consent was waived by the IRBs.

\section{Consent for publication}

Not applicable.

\section{Competing interests}

The authors declare that they have no competing interests.

\section{Author details}

'Department of Orthopaedics, Henan Provincial People's Hospital, Department of Orthopaedics of Central China Fuwai Hospital,Central China Fuwai Hospital of Zhengzhou University, No. 1, Fuwai Avenue, Zhengdong New District, Zhengzhou 450003, China. ${ }^{2}$ Department of Oral and Maxillofacial Surgery, The First Affiliated Hospital, Sun Yat-sen University, No. 58, Zhongshan 2nd Road, Yuexiu District, Guangzhou 510080, China. ${ }^{3}$ Department of Orthopaedics, Jinshan Hospital, Fudan University, No. 1508, Longhang Road, Jinshan District, Shanghai 201508, China. ${ }^{4}$ Department of Orthopaedics, The First Affiliated Hospital, Sun Yat-sen University, No. 58 Zhongshan 2nd Road, Yuexiu District, Guangzhou 510080, China.

Received: 30 August 2020 Accepted: 26 January 2021

Published online: 02 February 2021

\section{References}

1. Martin-Broto J, Hindi N, Lopez-Pousa A, Peinado-Serrano J, Alvarez R, Alvarez-Gonzalez A, Italiano A, Sargos P, Cruz-Jurado J, Isern-Verdum J, Dolado MC, Rincon-Perez I, Sanchez-Bustos P, Gutierrez A, Romagosa C, Morosi C, Grignani G, Gatti M, Luna P, Alastuey I, Redondo A, Belinchon B, Martinez-Serra J, Sunyach MP, Coindre JM, Dei Tos AP, Romero J, Gronchi A, Blay JY, Moura DS. Assessment of Safety and Efficacy of Combined Trabectedin and Low-Dose Radiotherapy for Patients With Metastatic SoftTissue Sarcomas A Nonrandomized Phase 1/2 Clinical Trial. JAMA Oncol. 2020;6(4):535-41.

2. Kendall GM, Bunch KJ, Stiller CA, Vincent TJ, MFG M. Case-control study of paternal occupational exposures and childhood bone tumours and softtissue sarcomas in Great Britain, 1962-2010. Br J Cancer. 2020;122(8):1250-9.

3. Blay JY, Blomqvist C, Bonvalot S, Boukovinas I, Casali PG, De Alava E, Dei Tos AP, Dirksen U, Duffaud F, Eriksson M, Fedenko A, Ferrari A, Ferrari S, Garcia del Muro X, Gelderblom H, Grimer R, Gronchi A, Hall KS, Hassan B,

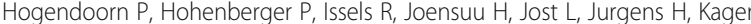
L, Le Cesne A, Leyvraz S, Martin J, Merimsky O, Nishida T, Picci P, Reichardt $P$, Rutkowski P, Schlemmer M, Sleijfer S, Stacchiotti S, Taminiau A, Wardelmann E, Grp EESNW. Soft tissue and visceral sarcomas: ESMO Clinical Practice Guidelines for diagnosis, treatment and follow-up. Ann Oncol. 2012; 23:92-9.

4. Hammer KJ, Copeland VC, Loggers ET, Pollack SM, Wagner MJ, Cranmer LD. Doxorubicin and Olaratumab Versus Doxorubicin, Ifosfamide, and Mesna for Treatment of Advanced Soft Tissue Sarcomas. Am J Clin Oncol-Cancer Clin Trials. 2020;43(6):446-51.

5. Chen YX, Zhu R, Chen M, Guo WN, Yang X, Xu XJ, Zhu LC. Prognostic Value of a Three-DNA Methylation Biomarker in Patients with Soft Tissue Sarcoma. J Oncol. 2020;2020:8106212.

6. Van Tine BA, Agulnik M, Olson RD, Walsh GM, Klausner A, Frank NE, Talley TT, Milhem MM. A phase II clinical study of 13-deoxy, 5-iminodoxorubicin (GPX-150) with metastatic and unresectable soft tissue sarcoma. Cancer Med. 2019;8(6):2994-3003.

7. D'Angelo SP, Mahoney MR, Van Tine BA, Atkins J, Milhem MM, Jahagirdar BN, Antonescu CR, Horvath E, Tap WD, Schwartz GK, Streicher H. Nivolumab with or without ipilimumab treatment for metastatic sarcoma (Alliance A091401): two open-label, non-comparative, randomised, phase 2 trials. Lancet Oncol. 2018;19(3):416-26.

8. Kato K, Cho BC, Takahashi M, Okada M, Lin C-Y, Chin K, Kadowaki S, Ahn MJ, Hamamoto Y, Doki Y, Yen C-C, Kubota Y, Kim S-B, Hsu C-H, Holtved E, Xynos I, Kodani M, Kitagawa Y. Nivolumab versus chemotherapy in patients with advanced oesophageal squamous cell carcinoma refractory or intolerant to previous chemotherapy (ATTRACTION-3): a multicentre, randomised, open-label, phase 3 trial. Lancet Oncol. 2019:20(11):1506-17.

9. Wang HY, Chu JF, Zhang P, Wang JQ, Yan Z, Yao SN, Yao ZH, Liu YY. Safety and Efficacy of Chemotherapy Combined with Anlotinib Plus Anlotinib Maintenance in Chinese Patients with Advanced/Metastatic Soft Tissue Sarcoma. Onco Targets Ther. 2020;13:1561-8.

10. Salah S, Abuhijla F, Ismail T, Yaser S, Sultan I, Halalsheh H, Shehadeh A, Abdelal S, Almousa A, Jaber O, Abu-Hijlih R. Outcomes of extraskeletal vs. skeletal Ewing sarcoma patients treated with standard chemotherapy protocol. Clin Transl Oncol. 2020;22(6):878-83. 
11. Paoluzzi L, Cacavio A, Ghesani M, Karambelkar A, Rapkiewicz A, Weber J, Rosen G. Response to anti-PD1 therapy with nivolumab in metastatic sarcomas. Clin Sarcoma Res. 2016;6:24.

12. Zer A, Icht O, Joseph L, Avram D, Jacobi O, Fenig E, Shamai S, Frommer RS, Bernstine H, Weitzen R, Bar-Sela G, Stemmer SM, Lotem M. A phase II singlearm study of nivolumab and ipilimumab (Nivo/lpi) in previously treated Classic Kaposi sarcoma (CKS). J Clin Oncol. 2019;37(15):11064.

13. Kim C, Kim EK, Jung H, Chon HJ, Han JW, Shin KH, Hu H, Kim KS, Choi YD, Kim S, Lee YH, Suh JS, Ahn JB, Chung HC, Noh SH, Rha SY, Kim SH, Kim HS. Prognostic implications of PD-L1 expression in patients with soft tissue sarcoma. BMC Cancer. 2016;16:434

14. Patel KR, Martinez A, Stahl JM, Logan SJ, Perricone AJ, Ferris MJ, Buchwald ZS, Chowdhary M, Delman KA, Monson DK, Oskouei SV, Reimer NB, Cardona K, Edgar MA, Godette KD. Increase in PD-L1 expression after pre-operative radiotherapy for soft tissue sarcoma. Oncoimmunology. 2018;7(7):e1442168.

15. D'Angelo SP, Larkin J, Sosman JA, Lebbe C, Brady B, Neyns B, Schmidt H, Hassel JC, Hodi FS, Lorigan P, Savage KJ, Miller WH Jr, Mohr P, MarquezRodas I, Charles J, Kaatz M, Sznol M, Weber JS, Shoushtari AN, Ruisi M, Jiang J. Wolchok JD. Efficacy and Safety of Nivolumab Alone or in Combination With Ipilimumab in Patients With Mucosal Melanoma: A Pooled Analysis. J Clin Oncol. 2017;35(2):226.

16. Gordon EM, Chua-Alcala VS, Kim K, Tseng WW, Quon DM, Chawla SP. Phase $1 / 2$ study of safety/efficacy using trabectedin, ipilimumab, and nivolumab as first- line treatment of advanced soft tissue sarcoma (STS). J Clin Oncol. 2018;36(5):TPS46.

17. Gordon EM, Sankhala KK, Stumpf N, Ravicz J, Arasheben S, Leong B, Kang G, Kim S, Tseng WW, Chawla SP. Cancer immunotherapy using trabectedin and nivolumab in advanced soft tissue sarcoma: A retrospective analysis. J Clin Oncol. 2018;36(5):40.

18. Hellmann MD, Ciuleanu TE, Pluzanski A, Lee JS, Otterson GA, AudigierValette C, Minenza E, Linardou H, Burgers S, Salman P, Borghaei H, Ramalingam SS, Brahmer J, Reck M, O'Byrne KJ, Geese WJ, Green G, Chang H, Szustakowski J, Bhagavatheeswaran P, Healey D, Fu Y, Nathan F, Paz-Ares L. Nivolumab plus Ipilimumab in Lung Cancer with a High Tumor Mutational Burden. N Engl J Med. 2018;378(22):2093-104.

19. Agulnik M, RLB C, Milhem M, Rademaker AW, Prunder BC, Daniels D, Rhodes BT, Humphreys C, Abbinanti S, Nye L, Cehic R, Polish A, Vintilescu C, McFarland T, Skubitz K, Robinson S, Okuno S, Van Tine BA. A phase II study of tivozanib in patients with metastatic and nonresectable soft-tissue sarcomas. Ann Oncol. 2017;28(1):121-7.

20. Postow MA, Chesney J, Pavlick AC, Robert C, Grossmann K, McDermott D, Linette GP, Meyer N, Giguere JK, Agarwala SS, Shaheen M, Ernstoff MS, Minor D, Salama AK, Taylor M, Ott PA, Rollin LM, Horak C, Gagnier P, Wolchok JD, Hodi FS. Nivolumab and Ipilimumab versus Ipilimumab in Untreated Melanoma. N Engl J Med. 2015;372(21):2006-17.

21. Wilky BA, Trucco MM, Subhawong TK, Florou V, Park W, Kwon D, Wieder ED, Kolonias D, Rosenberg AE, Kerr DA, Sfakianaki ER, Foley M, Merchan JR, Komanduri KV, Trent JC. Axitinib plus pembrolizumab in patients with advanced sarcomas including alveolar soft-part sarcoma: a single-centre, single-arm, phase 2 trial. Lancet Oncol. 2019;20(6):837-48.

22. Tawbi HA, Burgess M, Bolejack V, Van Tine BA, Schuetze SM, Hu J, D’Angelo S, Attia S, Riedel RF, Priebat DA, Movva S, Davis LE, Okuno SH, Reed DR, Crowley J, Butterfield LH, Salazar R, Rodriguez-Canales J, Lazar AJ, Wistuba BLH II, Maki RG, Reinke D, Patel S. Pembrolizumab in advanced soft-tissue sarcoma and bone sarcoma (SARC028): a multicentre, two-cohort, singlearm, open-label, phase 2 trial. Lancet Oncol. 2017;18(11):1493-501.

23. Zer A, Icht O, Jacobi O, Fenig E, Shamai S, Merimsky O, Shapira R, Bernstine H, Weitzen R, Vornikova O, Ben-Ami E, Bar-Sela G, Stemmer SM, Lotem M. A phase II single arm study of nivolumab and ipilimumab (Nivo/lpi) in previously treated Classical Kaposi Sarcoma (CKS). Ann Oncol. 2019;30:4040.

24. Chawla SP, Chua-Alcala VS, Kim K, Assudani N, Al-Shihabi A, Moradkhani A, Quon D, Wong S, Tseng WW, Pollack S, Srikureja AM, Jalas J, Jones RL, Gordon EM. The SAINT: Initial results of a phase I/II study of safety/efficacy using safe amounts of ipilimumab, nivolumab, and trabectedin as first-line treatment of advanced soft tissue sarcoma. J Clin Oncol. 2019;37(8):22.

25. Tamura K, Hasegawa K, Katsumata N, Matsumoto K, Mukai H, Takahashi S, Nomura $\mathrm{H}$, Minami $\mathrm{H}$. Efficacy and safety of nivolumab in Japanese patients with uterine cervical cancer, uterine corpus cancer, or soft tissue sarcoma: Multicenter, open-label phase 2 trial. Cancer Sci. 2019;110(9):2894-904.

26. D'Angelo SP, Mahoney MR, Van Tine BA, Atkins JN, Milhem MM, Tap WD, Antonescu CR, Horvath LE, Schwartz GK, Streicher H. A multi-center phase II study of nivolumab plus /- ipilimumab for patients with metastatic sarcoma (Alliance A091401). J Clin Oncol. 2017;35:11007.

27. Gordon EM, Chua-Alcala VS, Kim K, Andrali SS, Del Rosario M, Tseng WW. Phase 1/2 study of safety/efficacy using trabectedin, ipilimumab and nivolumab triple therapy as first line treatment of advanced soft tissue sarcoma. J Clin Oncol. 2018;36(15):TPS11591.

28. Tap WD, Jones RL, Van Tine BA, Chmielowski B, Elias AD, Adkins D, Agulnik M, Cooney MM, Livingston MB, Pennock G, Hameed MR, Shah GD, Qin A, Shahir A, Cronier DM, Ilaria R, Conti O, Cosaert J, Schwartz GK. Olaratumab and doxorubicin versus doxorubicin alone for treatment of soft-tissue sarcoma: an open-label phase $1 \mathrm{~b}$ and randomised phase 2 trial. Lancet. 2016;388(10043):488-97.

\section{Publisher's Note}

Springer Nature remains neutral with regard to jurisdictional claims in published maps and institutional affiliations.
Ready to submit your research? Choose BMC and benefit from:

- fast, convenient online submission

- thorough peer review by experienced researchers in your field

- rapid publication on acceptance

- support for research data, including large and complex data types

- gold Open Access which fosters wider collaboration and increased citations

- maximum visibility for your research: over $100 \mathrm{M}$ website views per year

At BMC, research is always in progress.

Learn more biomedcentral.com/submissions 